\title{
Modulation of Phosphate Absorption by Calcium in the Rabbit Proximal Convoluted Tubule
}

\author{
Diane Rouse and Wadi N. Suki \\ Renal Section, Department of Medicine, The Methodist Hospital and Baylor College of Medicine, Houston, Texas 77030
}

\begin{abstract}
Proximal convoluted $\left(\mathbf{S}_{2}\right)$ and straight $\left(\mathbf{S}_{3}\right)$ renal tubule segments were studied to determine the effect of $\mathrm{Ca}$ on lumen-to-bath phosphate flux $\left(\mathrm{J}_{\mathrm{PO}_{4}}^{\mathrm{b}}\right)$. Increasing bath and perfusate $\mathrm{Ca}$ from 1.8 to $3.6 \mathrm{mM}$ enhanced $J_{\mathrm{PO}_{4}}^{\mathrm{b}}$ from $3.3 \pm 0.7$ to $6.6 \pm 0.6 \mathrm{pmol} /$ mm per min in $S_{2}$ segments $(P<0.001)$ but had no effect in $\mathrm{S}_{3}$ segments. Decreasing bath and perfusate $\mathrm{Ca}$ from 1.8 to $0.2 \mathrm{mM}$ reduced $\mathrm{J}_{\mathrm{PO}_{4}}^{\mathrm{b}}$ from $3.7 \pm 0.6$ to $2.2 \pm 0.6$ in $\mathrm{S}_{2}$ segments. These effects were unrelated to changes in fluid absorption and transepithelial potential difference. Increasing cytosolic $\mathrm{Ca}$ with a $\mathrm{Ca}$ ionophore, inhibiting the $\mathrm{Ca}$-calmodulin complex with trifluoperazine, or applying the $\mathrm{Ca}$ channel blocker nifedipine had no effect on $\mathrm{J}_{\mathrm{PO}_{4}}^{\mathrm{lb}}$ in $\mathrm{S}_{2}$ segments. Increasing only bath $\mathrm{Ca}$ from 1.8 to $3.6 \mathrm{mM}$ did not significantly affect $\mathrm{J}_{\mathrm{PO}}^{\mathrm{b}}$. However, increasing only perfusate $\mathrm{Ca}$ enhanced $\mathrm{J}_{\mathrm{PO}}^{\mathrm{b}}$, from $3.4 \pm 0.7$ to $6.1 \pm 0.7 \mathrm{pmol} / \mathrm{mm}$ per $\min (P<0.005)$. Inhibition of hydrogen ion secretion, by using a low bicarbonate, low pH perfusate, both depressed base-line $\mathrm{J}_{\mathrm{PO}}^{\mathrm{b}}$, and abolished the stimulatory effect of raising perfusate Ca. Net phosphate efflux ( $\mathrm{J}_{\mathrm{PO}}^{\mathrm{pot}}$ ) also increased after ambient calcium levels were raised, ruling out a significant increase in $\mathrm{PO}_{4}$ backflux. When net sodium transport was abolished by reducing the bath temperature to $24^{\circ} \mathrm{C}, J_{\mathrm{PO}}^{\mathrm{pet}}$ at normal ambient calcium was reduced and increasing ambient calcium failed to increase it, ruling out a simple physicochemical reaction wherein phosphate precipitates out of solution with calcium.

The present studies provide direct evidence for a stimulatory effect of $\mathrm{Ca}$ on sodium-dependent $\mathrm{PO}_{4}$ absorption in the proximal convoluted tubule, exerted at the luminal membrane. It is postulated that $\mathrm{Ca}$ modulates the affinity of the $\mathrm{PO}_{4}$ transporter for the anion.
\end{abstract}

\section{Introduction}

The renal handling of phosphate may be influenced by a variety of factors, one of which is serum calcium concentration. Changes in serum calcium levels may alter renal phosphate absorption indirectly by altering the amount of phosphate

These studies were presented in preliminary form at the 14th and 15th Annual Meetings of the American Society of Nephrology, Chicago, December 1982, and Washington, DC, December; 1983; and at the 6th International Workshop on Phosphate and Other Minerals, Verona, Italy, June, 1983. They appeared in abstract form in 1982 (Proc. Am. Soc. Nephrology. 17) and in 1983 (Miner. Electrolyte Metab. 9:178).

Address reprint requests to Dr. Rouse.

Received for publication 18 September 1984 and in revised form 29 March 1985

J. Clin. Invest.

(c) The American Society for Clinical Investigation, Inc. 0021-9738/85/08/0630/07 \$1.00

Volume 76, August 1985, 630-636 filtered at the glomerulus. Infusion of calcium may increase the filtered load of phosphate by raising serum phosphate concentration (1-8). Opposing this effect is a decrease in the filterability of phosphate and in glomerular filtration rate (GFR). ${ }^{1}$ Filterable phosphate levels may decline as a result of the formation of calcium-phosphate-proteinate complexes $(9$, 10). The fall in GFR is due to not only a decline in renal plasma flow $(3,8,11,12)$ but also to a decline in the ultrafiltration coefficient (13). However, while the reduction in GFR reduces the filtered load of phosphate, it actually may enhance tubular absorption (14).

Changes in serum calcium also may indirectly alter tubular handling of phosphate. As serum calcium levels are raised, parathyroid hormone (PTH) secretion is inhibited, and the tubular absorption of phosphate increases $(2,4-7)$. Conversely, as serum calcium levels decline, PTH secretion increases and tubular absorption of phosphate declines $(15,16)$.

In addition to these indirect effects, clearance and micropuncture studies have suggested a direct effect of calcium on renal tubular absorption of phosphate. Clearance studies performed in hypoparathyroid humans have generally shown a decrease in phosphate absorption as serum calcium levels are raised acutely $(4,5,7)$ and an increase as serum calcium levels are lowered by EDTA infusion (17). Conversely, clearance studies in animals have shown an increase in phosphate absorption as serum calcium levels are increased $(11,18)$ and a decrease $(19,20)$ or no change $(21)$ as serum calcium levels are lowered, independently of PTH.

Micropuncture studies have not resolved the conflicting results of human and animal clearance studies. Amiel and colleagues (22) have shown that raising serum calcium levels from low towards normal in parathyroidectomized rats stimulates phosphate absorption in the proximal convoluted $\left(\mathrm{S}_{2}\right)$ tubule, loop of Henle, and the distal nephron. In the thyroparathyroidectomized dog, Goldfarb and colleagues (23) also found distal absorption of phosphate to be enhanced by mild hypercalcemia. In contrast to the study of Amiel et al., however, this group of investigators found that fractional phosphate absorption in the $S_{2}$ tubule was reduced. Using the standing droplet technique with simultaneous perfusion of peritubular capillaries in parathyroidectomized rats, Ullrich and colleagues (24) found that raising luminal calcium levels had no effect on phosphate transport in $S_{2}$ tubules in the absence of fluid absorption. However, these investigators did find a reduction in phosphate transport when calcium was eliminated from the perfusate. From these studies, it appears that as calcium delivery to the proximal tubule is increased

1. Abbreviations used in this paper: DMSO, dimethylsulfoxide; GFR, glomerular filtration rate; $J_{\mathrm{PO}}^{\mathrm{Jb}}$, lumen-to-bath phosphate flux; JM,

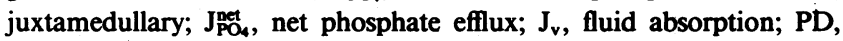
potential difference; PTH, parathyroid hormone; $S_{2}$, proximal convoluted; $S_{3}$, proximal straight; $S F$, superficial; TFP, trifluoperazine. 
from low to normal values, phosphate absorption increases. However, above normal values calcium may depress or have no effect on proximal phosphate absorption.

Thus, while there exists considerable evidence for a direct effect of calcium on the renal tubular absorption of phosphate, the direction of this effect remains uncertain. Since all of the previous studies have been performed in vivo, the indirect effects of calcium on phosphate delivery and absorption may have played a role in their outcome. For this reason, an in vitro study using the isolated tubule microperfusion technique was planned in an attempt to better understand the effects of calcium on renal phosphate handling. The first aim of the present study was to determine if phosphate absorption in the proximal tubule, the major site of phosphate absorption, was altered by changes in calcium concentration. Once the effect was clearly defined, the mechanism was then investigated.

\section{Methods}

\section{General procedure}

The general procedure used in the present studies is similar to that described previously (25) and is summarized below.

Female New Zealand White rabbits, fed a normal phosphate diet and allowed tap water ad lib., were killed by guillotine. Within $30 \mathrm{~min}$ of sacrifice, the left kidney was removed, transverse slices were made, and $S_{2}$ or proximal straight $\left(S_{3}\right)$ tubule segments dissected with careful attention to anatomical origin (superficial [SF] or juxtamedullary [JM]). The segments were then transferred to a lucite perfusion chamber and perfused according to the method of Burg et al. (26). All groups of tubules were studied at $38^{\circ} \mathrm{C}$ except for group XIV which was studied at $24^{\circ} \mathrm{C}$.

An artificial solution resembling plasma ultrafiltrate (" $A$ " solution, Table I) was used to perfuse and bathe the tubules. Solutions were gassed with $5 \% \mathrm{CO}_{2} / 95 \% \mathrm{O}_{2}$ to maintain a normal $\mathrm{pH}$ and $\mathrm{PCO}_{2}$. The perfusate and bath differed in the following ways.

Perfusate. To each perfusate was added exhaustively dialyzed [methoxy- ${ }^{3} \mathrm{H}$ ]inulin (Amersham Corp., Arlington Heights, IL) for the measurement of fluid absorption $\left(\mathrm{J}_{\mathrm{v}}\right)$ and ${ }^{32} \mathrm{P}$ (ICN Pharmaceuticals, Inc., Irvine, CA), for the measurement of lumen-to-bath phosphate flux $\left(\mathrm{J}_{\mathrm{PO}}^{\mathrm{b}}\right)$ or net phosphate efflux $\left(\mathrm{J}_{\mathrm{PO}_{4}}^{\mathrm{net}}\right)$. For two protocols, the calcium concentration was increased above that in the bath, and in one of these the bicarbonate was reduced to $8.0 \mathrm{mM}$ and the $\mathrm{pH}$ reduced to 6.8 .

Table I. Composition of A Solution*

\begin{tabular}{lc}
\hline Component & Millimoles per liter \\
\hline Sodium & 145.0 \\
Potassium & 5.0 \\
Chloride & 112.0 \\
Bicarbonate & 25.0 \\
Phosphate & 2.3 \\
Magnesium & 1.0 \\
Acetate & 10.0 \\
Sulfate & 1.0 \\
Glucose & 8.0 \\
d-Alanine & 5.0 \\
Calcium & 1.8 \\
Ionized calcium $(\mathrm{pH} 7.40)$ & 1.3
\end{tabular}

* An artificial solution resembling plasma ultrafiltrate.
Bath. To each $100 \mathrm{ml}$ of bath, $5 \mathrm{ml}$ of fetal calf sêrum (Gibco Laboratories, Grand Island, NY) was added. This small concentration of protein $(0.3 \mathrm{~g} / \mathrm{dl})$ did not alter the concentration of any component of the bath. For one protocol, the calcium concentration was increased above that in the perfusate. When $\mathrm{J}_{\mathrm{PO}}^{\mathrm{pet}}$ was measured, both bath and perfusate contained ${ }^{32} \mathrm{P}$ in identical concentration and specific activity.

Oils used to minimize evaporation were equilibrated with $\mathrm{H}_{2} \mathrm{O}$ saturated with $\mathrm{CO}_{2}$. To prevent evaporative water loss, the bath was exchanged continuously at $0.5 \mathrm{ml} / \mathrm{min}$. The reservoir of bath was continuously gassed with $5 \% \mathrm{CO}_{2} / 95 \% \mathrm{O}_{2}$ at $4^{\circ} \mathrm{C}$ so that the $\mathrm{pH}$ of the aliquot in the perfusion chamber was maintained at 7.4.

Transepithelial potential difference (PD) was meäured as described previously by Rocha and Kokko (27) and corrected for the calculated liquid junction potential (28) when appropriate. The voltage response to an imposed 50 meq/liter $\mathrm{NaCl}$ gradient (lumen greater than bath) was used to verify the origin of the tubule segments (29).

Timed fluid collections were made with a constant-volume constriction pipette, and each expelled into a counting vial containing 1 $\mathrm{ml}$ of water and $10 \mathrm{ml}$ of Biofluor (New England Nuclear, Boston, MA). The isotopic concentrations were determined in a liquid-scintillation spectrometer (Packard Instrument Co., Inc., United Technologies, Downers Grove, IL).

\section{Calculations}

$\mathrm{J}_{\mathrm{v}}$ in nanoliters per millimeter per minute was calculated using the following formula:

$J_{\mathrm{v}}=\frac{V_{\mathrm{i}}-V_{0}}{L}$,

where $V_{\mathrm{i}}$ and $V_{0}$ are the rates of perfusion and collection in nanoliters per minute, respectively, and $L$ is the length of the tubule segment in millimeters, as measured by a reticle in the eyepiece of the microscope used for perfusion.

$\mathrm{J}_{\mathrm{PO}_{4}}^{\mathrm{Ib}}$ and $\mathrm{J}_{\mathrm{PO}}^{\mathrm{pet}}$ in picoequivalents per millimeter per minute were calculated using the following balance formula:

$J_{\mathrm{PO}_{4}}=\left(\frac{V_{\mathrm{i}} C_{\mathrm{i}}-V_{0} C_{0}}{L}\right)\left(\frac{\left[\mathrm{PO}_{4}\right]_{\mathrm{i}}}{C_{\mathrm{i}}}\right)$

where $C_{\mathrm{i}}$ and $C_{0}$ are the disintegrations per minute per nanoliter in the perfusate and collected sample, respectively, and $\left[\mathrm{PO}_{4}\right]_{i}$ is the chemical concentration of phosphate in the perfusate in millimoles per liter.

The means of three to four collections from each of the control and experimental periods were compared statistically using the $t$ test for paired samples.

\section{Experimental protocols}

After a 30-40-min equilibration period, one of the following protocols was performed.

Group I. Five SF and six $\mathrm{JM} \mathrm{S}_{3}$ segments (mean length, $1.7 \pm 0.1$ $\mathrm{mm}$ ) were studied using first normal calcium concentration $(1.8 \mathrm{mM})$ in the bath and perfusate and then high calcium concentration (3.6 $\mathrm{mM}$ ) in the bath and perfusate. The order in which the tubules were exposed to normal and high calcium concentrations was alternated among experiments.

Group II. The protocol outlined in group I was repeated in five SF and five JM $S_{2}$ segments (mean length, $1.0 \pm 0.1 \mathrm{~mm}$ ).

Group III. Three SF and four JM $\mathrm{S}_{2}$ segments (mean length, $0.8 \pm 0.1 \mathrm{~mm}$ ) were studied using first normal calcium concentration in the bath and perfusate and then low calcium concentration $(0.2$ $\mathrm{mM}$ ) in the bath and perfusate.

Group IV. As a time control, four $\mathrm{SF}$ and four $\mathrm{JM} \mathrm{S}_{2}$ segments (mean length, $0.8 \pm 0.1 \mathrm{~mm}$ ) were studied using only normal calcium bath and perfusate over the same time intervals as groups I, II, and III.

Group $V$. Using normal calcium bath and perfusate, three SF and four $\mathrm{JM} \mathrm{S}_{2}$ segments (mean length, $0.9 \pm 0.1 \mathrm{~mm}$ ) were studied before 
and after the addition of the calcium ionophore A23187 (Sigma Chemical Co., St. Louis, MO) to both solutions to the final concentration of $5 \times 10^{-6} \mathrm{M}$. Control bath and perfusate contained the vehicle for the ionophore, dimethylsulfoxide (DMSO), in the same concentration as in the experimental solutions.

Group VI. The protocol outlined in group V was repeated in five $\mathrm{SF}$ and two JM $\mathrm{S}_{2}$ segments (mean length, $0.9 \pm 0.0 \mathrm{~mm}$ ) except that low calcium $(0.2 \mathrm{mM})$ perfusate and bath were used.

Group VII. The protocol outlined in group IV was repeated in four $\mathrm{SF}$ and two $\mathrm{JM} \mathrm{S}_{2}$ segments (mean length, $0.8 \pm 0.1 \mathrm{~mm}$ ) except that DMSO was added to the bath and perfusate in the same concentration as in groups $\mathrm{V}$ and $\mathrm{VI}$.

Group VIII. Four SF and three $\mathrm{JM} \mathrm{S}_{2}$ segments (mean length, $0.8 \pm 0.1 \mathrm{~mm}$ ) were studied before and after the addition of trifluoperazine (Sigma Chemical Co.), the Ca-calmodulin complex inhibitor, to a normal calcium bath and perfusate to the final concentration of $10^{-4}$ or $10^{-6} \mathrm{M}$.

Group IX. Using normal calcium bath and perfusate, four SF and four JM $\mathrm{S}_{2}$ segments (mean length, $0.9 \pm 0.1 \mathrm{~mm}$ ) were studied before and after the addition of the calcium channel blocker nifedipine to the perfusate to the concentration of $10^{-6} \mathrm{M}$.

Group $X$. Three SF and two JM $\mathrm{S}_{2}$ segments (mean length, $0.8 \pm 0.1$ $\mathrm{mm}$ ) were studied before and after raising only the bath calcium concentration from 1.8 to $3.6 \mathrm{mM}$. Perfusate calcium was $1.8 \mathrm{mM}$ throughout.

Group XI. The protocol outlined in group $\mathrm{X}$ was repeated in one $\mathrm{SF}$ and four JM $S_{2}$ segments (mean length, $0.6 \pm 0.1 \mathrm{~mm}$ ) except that perfusate calcium concentration was raised to $3.6 \mathrm{mM}$. Bath calcium was $1.8 \mathrm{mM}$ throughout.

Group XII. The effect of raising only perfusate calcium was again studied in two SF and four JM $S_{2}$ segments (mean length, $0.8 \pm 0.1$ $\mathrm{mm}$ ) except a perfusate resembling late proximal tubule luminal fluid was used. The bicarbonate of this perfusate was $8.0 \mathrm{mM}$ and the pH 6.8.

Group XIII. In two SF and three JM S $\mathrm{S}_{2}$ segments (mean length, $0.98 \pm 0.08 \mathrm{~mm}$ ), $\mathrm{J}_{\mathrm{PO}_{4}}^{\text {net }}$ was measured using normal and high calcium concentrations in the bath and perfusate.

Group XIV. The protocol used in group XIII was repeated in three $\mathrm{SF}$ and three JM $\mathrm{S}_{2}$ segments (mean length, $0.8 \pm 0.1 \mathrm{~mm}$ ) except the temperature of the bath was reduced to $24^{\circ} \mathrm{C}$.

\section{Results}

The responses of SF and JM tubule segments were identical in all 14 groups studied and thus were combined for statistical analysis.

\section{Effect of Increasing or Decreasing Ambient Calcium}

In $\mathrm{S}_{\mathbf{3}}$ tubule segments (group I), increasing bath and perfusate $\mathrm{Ca}$ from 1.8 to $3.6 \mathrm{mM}$ had no significant effect on $J_{v}, P D$, or $\mathrm{J}_{\mathrm{PO}_{4}}^{\mathrm{b}} \cdot \mathrm{J}_{\mathrm{v}}$ was $0.3 \pm 0.1 \mathrm{nl} / \mathrm{mm}$ per min using $1.8 \mathrm{mM} \mathrm{Ca}$ and $0.2 \pm 0.1$ using $3.6 \mathrm{mM} \mathrm{Ca}$; PD was $-0.7 \pm 0.1 \mathrm{mV}$ using either $\mathrm{Ca}$ concentration; and $\mathrm{J}_{\mathrm{PO}_{4}}^{\mathrm{Jb}}$ was $1.2 \pm 0.2 \mathrm{pmol} / \mathrm{mm}$ per min for both concentrations. However, identical experiments performed in $\mathrm{S}_{2}$ tubule segments (group II) revealed an increase of $\mathrm{J}_{\mathrm{PO}_{4}}^{\mathrm{bb}}$ from $3.3 \pm 0.7$ to $6.6 \pm 0.6(P<0.001)$ as ambient $\mathrm{Ca}$ was increased (Table II). In these experiments, $J_{v}$ and PD were stable after raising ambient $\mathrm{Ca}$. When bath and perfusate $\mathrm{Ca}$ were lowered from 1.8 to $0.2 \mathrm{mM}$ in $\mathrm{S}_{2}$ segments (group III), $\mathrm{J}_{\mathrm{PO}_{4}}^{\mathrm{lb}}$ fell from $3.7 \pm 0.6$ to $2.2 \pm 0.6 \mathrm{pmol} / \mathrm{mm}$ per $\min (P$ $<0.05$ ) (Table II). PD was unchanged; however, $J_{v}$ increased from $0.6 \pm 0.1$ to $0.8 \pm 0.1 \mathrm{nl} / \mathrm{mm}$ per $\min (P<0.05)$ as ambient Ca was decreased, an effect also observed by Friedman and colleagues (30).

Time control studies in $S_{2}$ segments, using only normal ambient Ca (group IV), revealed no changes in $J_{v}, P D$, or $\mathrm{J}_{\mathrm{PO}_{4}}^{\mathrm{b}}$.

\section{Mechanism by Which Calcium Modulates $\mathrm{PO}_{4}$ Reabsorption}

Cytosolic changes. With the use of normal ambient $\mathrm{Ca}$ in seven $\mathrm{S}_{2}$ segments (group V), the Ca ionophore A21387 was added to the perfusate and bath to increase cytosolic $\mathrm{Ca}$ (31) and mimic the effect of increasing ambient $\mathrm{Ca}$. PD declined from $-0.9 \pm 0.1 \mathrm{mV}$ in control to $-0.4 \pm 0.1 \mathrm{mV}(P<0.01)$, and $J_{\mathrm{v}}$ increased from $0.8 \pm 0.1 \mathrm{nl} / \mathrm{mm}$ per $\min$ to $1.3 \pm 0.1$ $(P<0.005)$ with the addition of ionophore (Table III). Despite these changes, $\mathrm{J}_{\mathrm{PO} 4}^{\mathrm{lb}}$ was not significantly altered, being $3.7 \pm 0.6$

Table II. Relationship of Bath and Perfusate Calcium Concentrations and $\mathrm{J}_{P O_{4}}^{\text {lb }}$ in $\mathrm{S}_{2}$ Segments

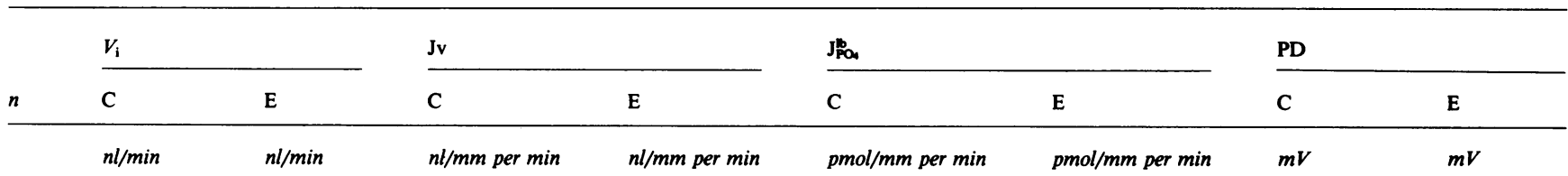

Bath and perfusate $\mathrm{Ca}$ increased from $1.8(\mathrm{C})$ to $3.6(\mathrm{E}) \mathrm{mM}$

$\begin{array}{lllll}10 & 25.0+1.5 & 25.8+1.4 & 0.6 \pm 0.1 & 0.5 \pm 0.1\end{array}$

$3.3 \pm 0.7$

$-1.0 \pm 0.2$

$-1.3 \pm 0.3$

Bath and perfusate Ca decreased from $1.8(\mathrm{C})$ to $0.2(\mathrm{E}) \mathrm{mM}$

7

$19.5 \pm 1.4$

$0.6 \pm 0.1$

$0.8 \pm 0.1^{*}$

$3.7 \pm 0.6$

$2.2 \pm 0.6^{*}$

$-1.2 \pm 0.3$

$-0.9 \pm 0.3$

Bath Ca increased from 1.8 (C) to $3.6(\mathrm{E}) \mathrm{mM}$

$\begin{array}{llll}5 & 19.7 \pm 1.3 & 18.6 \pm 0.5 & 0.8 \pm 0.1\end{array}$

$0.7 \pm 0.1$

$3.9 \pm 0.8$

$3.3 \pm 0.7$

$-1.1 \pm 0.2$

$-1.4 \pm 0.3$

Perfusate Ca increased from 1.8 (C) to 3.6 (E) $\mathrm{mM}$

$19.3 \pm 2.0 \quad 19.7 \pm 2.3 \quad 1.2 \pm 0.2$

$0.9 \pm 0.2$

$3.4 \pm 0.7$

$6.1 \pm 0.7^{*}$

$-1.7 \pm 0.4$

$-1.5 \pm 0.4$

$V_{\mathrm{i}}$ is perfusion rate. ${ }^{*}$ Denotes a significant difference between control $(\mathrm{C})$ and experimental $(\mathrm{E})$ periods. 
Table III. Mechanism by Which Calcium Stimulates Phosphate Efflux in $S_{2}$ Segments

\begin{tabular}{|c|c|c|c|c|c|c|c|c|}
\hline \multirow[b]{2}{*}{$n$} & \multicolumn{2}{|l|}{$V_{\mathrm{i}}$} & \multicolumn{2}{|l|}{$\mathbf{J}_{\mathbf{v}}$} & \multicolumn{2}{|l|}{$\mathrm{J}_{\mathrm{Pa}}$} & \multicolumn{2}{|l|}{ PD } \\
\hline & c & E & C & $\mathbf{E}$ & C & E & C & $\mathbf{E}$ \\
\hline & $n l / \min$ & $n l / \min$ & $\mathrm{nl} / \mathrm{mm}$ per $\mathrm{min}$ & $n l / m m$ per min & pmol/mm per min & pmol/mm per min & $m V$ & $m V$ \\
\hline
\end{tabular}

$\mathrm{J}_{\mathrm{PO} 4}^{\mathrm{b}}$ after addition of ionophore (E), group $\mathrm{V}$

$\begin{array}{llll}7 & 25.5 \pm 1.3 & 26.3 \pm 0.9 & 0.8 \pm 0.1\end{array}$

$1.3 \pm 0.1^{*} \quad 3.7 \pm 0.6$

$4.7 \pm 1.0$

$-0.9 \pm 0.1 \quad-0.4 \pm 0.1^{*}$

$\mathrm{JPO}_{\mathrm{P}}^{\mathrm{b}}$ after addition of TFP (E), group VIII

$\begin{array}{lll}7 & 21.5 \pm 1.9 & 20.0 \pm 2.0\end{array}$

$0.4 \pm 0.0^{*} \quad 4.5 \pm 0.4$

$3.8 \pm 0.5$

$-1.5 \pm 0.5 \quad-0.2 \pm 0.2^{*}$

$\mathrm{J}_{\mathrm{PO}_{4}}^{\mathrm{b}}$ after addition of nifedipine (E), group IX

$\begin{array}{llll}8 & 16.5 \pm 0.8 & 17.4 \pm 0.5 & 1.0 \pm 0.1\end{array}$

$0.9 \pm 0.3 \quad 5.1 \pm 0.6$

$4.5 \pm 0.3$

$-1.2 \pm 0.1 \quad-1.0 \pm 0.2$

$\mathrm{J}_{\mathrm{PO} 4}^{\mathrm{b}}$ after increasing perfusate calcium (E), absence of $\mathrm{H}^{+}$secretion, group XII

$\begin{array}{llll}16.4 \pm 1.0 & 16.7 \pm 1.4 & 0.8 \pm 0.2 & 0.7 \pm 0.1\end{array}$

$.4 \pm 0.3$

$2.1 \pm 0.3$

$-0.7 \pm 0.5$

$-0.5 \pm 0.6$

$\mathrm{J}_{\mathrm{PO}_{4}}^{\text {net }}$ using $1.8(\mathrm{C})$ and 3.6 (E) $\mathrm{mM}$ ambient calcium, group XIII

5

$17.9 \pm 1.0$

$1.2 \pm 0.3$

$1.0 \pm 0.2$

$3.9 \pm 0.8$

$6.5 \pm 1.3^{*}$

$-2.1 \pm 0.5 \quad-1.5 \pm 0.3$

$\mathrm{J}_{\mathrm{PO}_{4}}^{\mathrm{net}}$ in the absence of a sodium gradient, using 1.8 (C) and 3.6 (E) $\mathrm{mm}$ ambient calcium, group XIV

\begin{abstract}
$18.2 \pm 0.6$
$16.9 \pm 0.8$
\end{abstract}

$0.11 \pm 0.07$

$0.17 \pm 0.06$

$1.2 \pm 0.3$

$1.2 \pm 0.4$

$-0.3 \pm 0.1$

$-0.3 \pm 0.8$

Definition of terms same as in Table II. $\mathrm{J}_{\mathrm{PO}}$, phosphate flux, both net and lumen-to-bath. ${ }^{*}$ Denotes a significant difference between $\mathrm{C}$ and $\mathrm{E}$ periods.

$\mathrm{pmol} / \mathrm{mm}$ per min before and $4.7 \pm 1.0$ after the addition of ionophore. The effect of ionophore was studied in an additional seven $\mathrm{S}_{2}$ segments maintained in low ambient $\mathrm{Ca}(0.2 \mathrm{mM})$ (group VI). Again, PD fell from $-1.3 \pm 0.3$ to $-0.7 \pm 0.2 \mathrm{mV}$ with the addition of ionophore $(P<0.05)$; however, $\mathrm{J}_{\mathrm{v}}$ was unchanged, being $0.9 \pm 0.1 \mathrm{nl} / \mathrm{mm}$ per min before and after the addition of ionophore. Although basal $\mathrm{J}_{\mathrm{PO}}^{\mathrm{lb}}$ was lower due to the lower ambient calcium, the addition of ionophore failed to stimulate the $\mathrm{J}_{\mathrm{PO}_{4}}^{\mathrm{b}}$, being $2.8 \pm 0.6 \mathrm{pmol} / \mathrm{mm}$ per min before and $2.7 \pm 0.5$ after ionophore addition.

Six $\mathrm{S}_{2}$ segments were studied as time controls (group VII), as in group IV, except that the vehicle for the ionophore, DMSO, was added to the bath and perfusate. $J_{v}, P D$, and $\mathrm{J}_{\mathrm{PO}_{4}}^{\mathrm{lb}}$ were not significantly altered.

Changes in ambient $\mathrm{Ca}$ may alter cytosolic processes that require $\mathrm{Ca}$. To test the possibility that the activation of $\mathrm{Ca}$ calmodulin-dependent reactions stimulates $\mathrm{PO}_{4}$ absorption $\mathrm{S}_{2}$ segments were studied before and after the addition of trifluoperazine (TFP) to a normal $\mathrm{Ca}$ bath and perfusate. With the addition of TFP, $J_{v}$ declined from $0.7 \pm 0.1$ to $0.4 \pm 0.0 \mathrm{nl} / \mathrm{min}$ per $\min (P<0.025)$, as did PD from $-1.5 \pm 0.4 \mathrm{mV}$ to $-0.2 \pm 0.2$ after TFP addition $(P<0.05)$ (Table III). Despite these changes, $\mathrm{J}_{\mathrm{PO}_{4}}^{\mathrm{lb}}$ was unchanged, being $4.5 \pm 0.4 \mathrm{pmol} / \mathrm{mm}$ per $\mathrm{min}$ in control and $3.8 \pm 0.5 \mathrm{pmol} / \mathrm{mm}$ per $\mathrm{min}$ after TFP was added.

To block $\mathrm{Ca}$ entry and lower cytosolic $\mathrm{Ca}$, nifedipine, a calcium channel blocker in smooth and cardiac muscle, was added to the perfusate in eight $S_{2}$ segments (group IX). $J_{v}$, $\mathrm{PD}$, and $\mathrm{J}_{\mathrm{PO}_{4}}^{\mathrm{lb}}$ were not affected by the calcium channel blocker (Table III). The lack of effect of nifedipine addition may only indicate that the calcium channels of this epithelium are not blocked by this compound. Calcium fluxes were not determined to verify this effect of nifedipine.

Membrane alterations. To determine the sidedness of the effect of calcium on phosphate absorption, the calcium concentration was raised in the bath (group X) and perfusate (group XI) separately. When bath calcium was increased from 1.8 to $3.6 \mathrm{mM}$, neither $\mathrm{J}_{\mathrm{v}}, \mathrm{PD}$, nor $\mathrm{J}_{\mathrm{PO}}^{\mathrm{lb}}$ was significantly altered (Table II). By contrast, increasing perfusate $\mathrm{Ca}$ significantly enhanced $\mathrm{J}_{\mathrm{PO}_{4}}^{\mathrm{lb}}$ from $3.4 \pm 0.7$ to $6.1 \pm 0.7 \mathrm{pmol} / \mathrm{mm}$ per min $(P<0.005)$ (Table II), an effect comparable to that seen when both perfusate and bath calcium concentrations were raised (group II, Table II) simultaneously. Neither $\mathrm{J}_{\mathbf{v}}$ nor PD was altered by increasing perfusate $\mathrm{Ca}$.

Changes in $p H$. To study the possibility that Ca stimulates $\mathrm{PO}_{4}$ absorption by stimulating $\mathrm{H}^{+}$secretion in $\mathrm{S}_{2}$ segments, perfusate $\mathrm{Ca}$ concentrations were again increased, except a low bicarbonate $(8.0 \mathrm{mM})$ low $\mathrm{pH}(6.8)$ perfusate-simulating late proximal tubule luminal fluid was employed (group XII). Using this perfusate, $\mathrm{H}^{+}$secretion should have been abolished. Increasing perfusate $\mathrm{Ca}$ from 1.8 to $3.6 \mathrm{mM}$ in this setting failed to stimulate $\mathrm{J}_{\mathrm{PO}}^{\mathrm{Jb}}$, which was $2.4 \pm 0.3$ before and $2.1 \pm 0.2$ $\mathrm{pmol} / \mathrm{mm}$ per min after perfusate $\mathrm{Ca}$ concentrations were raised. Neither $J_{v}$ nor $P D$ was significantly altered by increasing perfusate $\mathrm{Ca}$ concentrations (Table III). However, basal $\mathrm{J}_{\mathrm{PO}}^{\mathrm{lb}}$ was depressed by the low bicarbonate low $\mathrm{pH}$ perfusate, the value observed being lower than those observed in the other study groups.

Net efflux studies. An increase in medium calcium may be expected to increase the concentration of the complex $\mathrm{CaHPO}_{4}$, which may permeate both the luminal and basolateral membrane more easily than a charged $\mathrm{PO}_{4}$ species. Measuring only 
unidirectional $\mathrm{PO}_{4}$ efflux ignores the possibility of enhanced influx; thus, net efflux studies were performed. At bath temperature of $38^{\circ} \mathrm{C}$, $\mathrm{J}_{\mathrm{PO}_{4}}^{\mathrm{net}}$ was $3.9 \pm 0.8 \mathrm{pmol} / \mathrm{mm}$ per min with the use of normal ambient calcium and $6.5 \pm 1.3 \mathrm{pmol} / \mathrm{mm}$ per min with the use of high ambient calcium $(P<0.05$, Table III). Again, no significant changes in PD or $J_{v}$ were observed. These results are similar to those of the unidirectional efflux studies (group II), which used normal and high ambient calcium.

The final group of tubules was studied at $24^{\circ} \mathrm{C}$ to determine if calcium stimulates sodium-dependent $\mathrm{PO}_{4}$ transport, and if the apparent stimulation is due to precipitation and/or binding of $\mathrm{Ca}-\mathrm{PO}_{4}$ complexes at the brush border villi. The absence of net sodium transport was confirmed by the low $\mathrm{J}_{\mathrm{v}}$ and PD (Table III). $\mathrm{J}_{\mathrm{PO}_{4}}^{\text {net }}$ was also reduced to $1.2 \pm 0.3 \mathrm{pmol} / \mathrm{mm}$ per min with the use of normal ambient $\mathrm{Ca}$ and was unchanged when ambient $\mathrm{Ca}$ was increased to $3.6 \mathrm{mM}$ being $1.2 \pm 0.4$ $\mathrm{pmol} / \mathrm{mm}$ per $\mathrm{min}$.

\section{Discussion}

While a direct relationship between the concentration of calcium in the serum and phosphate absorption in the proximal tubule has been described, its nature is controversial. Previous studies were performed in vivo and their results may have reflected not only changes in serum calcium concentrations but also changes in other variables induced by calcium infusion. The present study was designed to examine the effect of calcium on phosphate handling in the proximal tubule in vitro, in the absence of any influence of alterations in renal hemodynamics or serum phosphate.

The results of this study demonstrate that the magnitude of sodium-dependent phosphate absorption in the proximal convoluted tubule is directly related to the calcium concentration of the luminal fluid. Alterations of cytosolic calcium by the addition of a calcium ionophore or inhibition of the calcium-calmodulin complex did not mimic the effects seen when ambient calcium was varied.

These results are consistent with those of Amiel and colleagues (22) and of Frick and Durasin (32) in the rat, but not with those of Goldfarb et al. (23) in the dog, and Ullrich et al. (24) in the rat. However, in the study of Goldfarb et al., as hypercalcemia was induced, serum phosphate rose and fractional phosphate absorption declined. While ultrafilterable calcium and phosphate increased as well, it is possible that this pair may have been in some form of ion association that is not available for transport. Species differences also may account for the discrepancy between the results of Amiel et al. and of the present studies, and those of Goldfarb et al. The apparent discrepancy with the results of Ullrich et al. may be explained by the lack of net sodium absorption in their study. Our results indicate that calcium stimulates the sodiumdependent but not passive phosphate absorption.

Popovtzer et al. (18), in the rat, and Glorieux and Scriver (33), in familial hypophosphatemic patients, have suggested two mechanisms for phosphate absorption in the nephron. One mechanism appears to be stimulated by calcium and inhibited by saline expansion; the other inhibited by PTH. The distribution of these mechanisms along the nephron may vary among the species. In the proximal tubule of the rabbit, unlike that of the rat and dog, PTH does not inhibit phosphate absorption in the early convolutions and has a moderate or no effect in later convolutions $(34,35)$. Perhaps in the rabbit, the absorption of phosphate in the $S_{2}$ tubule is controlled primarily by the calcium-stimulated mechanism. In the $S_{3}$ tubule segment of the rabbit, PTH does inhibit phosphate absorption (34). Our studies indicate that calcium does not modulate phosphate absorption in this segment, thus, PTH may be the primary control in this portion of the rabbit nephron.

The lack of effect of the calcium ionophore is not surprising. McKeown (36) presented similar results in their studies using the calcium ionophore and normal ambient calcium. Popovtzer et al. (37) and Ullrich et al. (24) also found no effect of the ionophore on phosphate absorption in vivo without the influence of PTH. The effect of the ionophore on $J_{v}$ is not consistent among these studies, however. McKeown (36) found an enhancement of $J_{v}$ very similar to ours, and Ullrich et al. (24) and Friedman et al. (30) found an inhibition with ionophore addition. Information to date offers no explanation for these discrepancies. Friedman et al.'s and Ullrich et al.'s results support the sodium-calcium antiport theory, whereas McKeown's and the present studies do not.

The results obtained with the calcium-calmodulin complex inhibitor were not expected. The addition of TFP produced a significant decline in PD and $J_{v}$ but no depression of phosphate absorption. The decline in PD and $J_{v}$ is indicative of reduced sodium absorption. One possible explanation for these results is that the calcium-calmodulin-stimulated phosphodiesterase (38) activity was reduced resulting in an increase in intracellular cAMP, which is known to inhibit sodium and fluid absorption (39). Not consistent with this interpretation, however, is the lack of effect on phosphate absorption. Agus and colleagues (39) found an inhibition of phosphate as well as sodium absorption with cAMP infusion in the dog. Also, Brazy et al. (35) have shown that PTH, which presumably acts by stimulating CAMP production, does moderately inhibit fluid and phosphate absorption in late $S_{2}$ tubule segments from the rabbit. The lack of effect of TFP on phosphate absorption in our studies suggests that calcium acts independently of cAMP to modulate this process.

Kessler et al. (40) have isolated a 3,000-mol-wt proteolipid from brush border membrane vesicles from rabbit renal cortex which exhibits sodium-dependent phosphate binding. The Michaelis constant for binding is $8 \mu \mathrm{M}$ phosphate, while saturation occurs at $20 \mu \mathrm{M}$. A further report by this group has shown that phosphate binding by this proteolipid is dependent on divalent metal ions, manganese and calcium, sharing the highest order of effectiveness (41). If this proteolipid is, indeed, the phosphate transporter, calcium may stimulate phosphate transport by activating this transporter. Alternatively, calcium may act by recruiting additional proteolipid units.

The level of serum calcium has been shown to affect hydrogen ion secretion in the kidney. Lowering serum calcium levels inhibits hydrogen ion secretion in thyroparathyroidectomized dogs (20) and isolated rabbit proximal tubules perfused in vitro (42), while raising serum calcium levels stimulates secretion in thyroparathyroidectomized dogs (43). One possible mechanism by which increases in calcium enhance phosphate absorption is by this stimulation of hydrogen ion secretion. Increasing hydrogen ion concentration may titrate the dibasic ion to its monobasic form, reduce its polarity, and promote its entry into the cell. Indeed, in our studies, when calcium concentration was raised in an acid perfusate which limits $\mathbf{H}^{+}$ 
secretion, $\mathrm{J}_{\mathrm{PO}}^{\mathrm{lb}}$ did not increase, and $\mathrm{PD}$ and $\mathrm{J}_{\mathrm{v}}$ did not change. It is not likely, however, that calcium augments phosphate absorption by acidifying the luminal contents, since basal flux with the low bicarbonate perfusate was lower than that with the normal bicarbonate perfusate. This observation is of interest and has been shown in other studies where $\mathrm{pH}$ and bicarbonate were varied $(44,45)$. The decline in phosphate absorption when the luminal contents are acid, along with studies on phosphate uptake by brush border (luminal) membrane vesicles $(46,47)$, has been taken as evidence that the divalent phosphate species is preferentially transported. However, phosphate absorption also declines as luminal $\mathrm{pH}$ is increased above 7.5 (44). The similar effects of the two extremes in $\mathrm{pH}$ suggest that there is a modification of a membrane component rather than promotion of the divalent or monovalent species. In contrast to our study and those of others $(44,45)$, Hamm and colleagues (48) have shown an increase in phosphate absorption when the perfusate $\mathrm{pH}$ was lowered from 7.4 to 6.2 in the presence or absence of bicarbonate. The different results of Hamm et al. may be related to the concentration of phosphate used in their study, which was $10 \mathrm{mM}$ vs. the $2.3 \mathrm{mM}$ used in our study and those of Dennis et al. (44). In the study of Hamm et al. lowering $\mathrm{pH}$ from 7.4 to 6.2 reduces the concentration of the divalent phosphate species from 8 to 2 $\mathrm{mM}$, whereas in our study the concentration fell from 1.8 to $1.2 \mathrm{mM}$ and in the study of Dennis et al. (44) from 1.8 to 0.7 $\mathrm{mM}$. The lower concentrations of the divalent species in the latter studies may account for the reduction in phosphate absorption.

In conclusion, the present study shows that increasing ambient calcium stimulates sodium-dependent phosphate absorption in the $S_{2}$ tubule of the rabbit, whereas lowering ambient calcium inhibits phosphate absorption. There is no effect when calcium levels are raised in $S_{3}$ tubule segments. The effect in the convoluted tubule segments does not appear to be mediated by changes in cytosolic ionized calcium but instead appears to occur at the luminal membrane. Calcium translocation and stimulation of hydrogen ion secretion by calcium do not appear to modulate phosphate absorption, although the inhibition of calcium translocation was not verified. The present results are consistent with a role for calcium in modulating the affinity of the luminal phosphate transporter for the anion.

\section{Acknowledgments}

The suggestions and encouragement of Dr. Robert A. Peraino and the secretarial assistance of Mrs. Laura Pritchard are gratefully acknowledged.

This work was supported by National Institutes of Health grant AM 21394.

\section{References}

1. Salvesen, H. A., A. B. Hastings, and J. F. McIntosh. 1924. The effect of the administration of calcium salts on the inorganic composition of the blood. J. Biol. Chem. 60:327-339.

2. Baylor, C. H., H. E. Van Alstine, E. H. Keutman, and S. H. Bassett. 1950. The fate of intravenously administered calcium. Effect of urinary calcium and phosphorus, fecal calcium and calcium-phosphorus balance. J. Clin. Invest. 29:1167-1176.

3. Chen, P. S., Jr., and W. F. Neuman. 1955. Renal secretion of calcium by the dog. Am. J. Physiol. 180:623-631.
4. Hiatt, W. H., and D. D. Thompson. 1957. Some effects of intravenously administered calcium on inorganic phosphate metabolism. J. Clin. Invest. 36:573-580.

5. Howard, J. E., T. R. Hopkins, and T. B. Connor. 1953. On certain physiologic responses to intravenous injection of calcium salts into normal, hyperparathyroid and hypoparathyroid persons. J. Clin. Endocrinol. Metab. 13:1-19.

6. Kyle, L. H., M. Schaaf, and L. A. Erdman. 1954. The metabolic effects of intravenous administration of calcium. J. Lab. Clin. Med. 43:123-133.

7. Nordin, B. E., and R. Fraser. 1954. The effect of intravenous calcium on phosphate excretion. Clin. Sci. (Lond.). 13:477-490.

8. Wallach, S., and A. C. Carter. 1961. Metabolic and renal effects of acute hypercalcemia in dogs. Am. J. Physiol. 200:359-366.

9. Grollman, A. 1927. The condition of the inorganic phosphorus of the blood with special reference to the calcium concentration. $J$. Biol. Chem. 72:565-572.

10. Hopkins, T., J. E. Howard, and H. Eisenberg. 1952. Ultrafiltration studies on calcium and phosphorus in human serum. Johns Hopkins Med. J. 91:1-21.

11. Lavender, A. R., and T. N. Pullman. 1963. Changes in inorganic phosphate excretion induced by renal arterial infusion of calcium. Am. J. Physiol. 205:1025-1032.

12. Chomdej, B., P. D. Bell, and L. G. Navar. 1977. Renal hemodynamics and autoregulatory responses to acute hypercalcemia. Am. J. Physiol. 232:F490-F496.

13. Humes, H. D., I. Ichikawa, J. L. Troy, and B. M. Brenner. 1978. Evidence for a parathyroid hormone dependent influence of calcium on the glomerular ultrafiltration coefficient. J. Clin. Invest. 61:32-40.

14. Puschett, J. B., Z. S. Agus, D. Senesky, and M. Goldberg. 1972. Effects of saline loading and aortic obstruction on proximal phosphate transport. Am. J. Physiol. 223:851-857.

15. Greenwald, I., and J. Gross. 1925. The effect of the administration of a potent parathyroid extract upon the excretion of nitrogen, phosphorus, calcium, and magnesium, with some remarks on the solubility of calcium phosphate in serum and on pathogenesis of tetany. J. Biol. Chem. 66:217-227.

16. Pullman, T. N., A. R. Lavender, I. Aho, and H. Rasmussen. 1960. Direct renal action of a purified parathyroid extract. Endocrinology. 67:570-582.

17. Estep, H. L., C. T. Gardner, Jr., J. P. Taylor, A. Minott, and H. St. G. Tucker, Jr. 1965. Phosphate excretion patterns following intravenous injection of ethylenediaminetetraacetate (EDTA). J. Clin. Endocrinol. Metab. 25:1385-1392.

18. Popovtzer, M. M., J. B. Robinette, K. M. McDonald, and C. K. Kuruvila. 1975. Effect of $\mathrm{Ca}^{++}$on renal handling of $\mathrm{PO}^{3-}$ : evidence for two reabsorptive mechanisms. Am. J. Physiol. 449:901-906.

19. Rasmussen, H., C. Anast, and C. Arnaud. 1967. Thyrocalcitonin, EGTA, and urinary electrolyte excretion. J. Clin. Invest. 46:746-752.

20. Rouse, D., S. Sessoms, B. J. Stinebaugh, and W. N. Suki. 1984. The effect of hypocalcemia on renal bicarbonate absorption. Miner. Electrolyte Metab. 10:31-35.

21. Cuche, J. L., C. E. Ott, G. R. Marchand, and F. G. Knox. 1976. Lack of effect of hypocalcemia on renal phosphate handling. $J$. Lab. Clin. Med. 88:271-275.

22. Amiel, C., H. Kuntziger, S. Couette, C. Coureau, and N. Bergounioux. 1976. Evidence for a parathyroid hormone-independent calcium modulation of phosphate transport along the nephron. J. Clin. Invest. 57:256-263.

23. Goldfarb, S., P. Bosanac, M. Goldberg, and Z. S. Agus. 1978. Effects of calcium on renal tubular phosphate reabsorption. Am. J. Physiol. 234:F22-F28.

24. Ullrich, K. J., G. Rumrich, and S. Kloss. 1978. Phosphate transport in the proximal convolution of the rat kidney. Pfluegers Arch. 375:97-103.

25. Rouse, D., R. C. K. Ng, and W. N. Suki. 1980. Calcium 
transport in the pars recta and thin descending limb of Henle of the rabbit, perfused in vitro. J. Clin. Invest. 65:37-42.

26. Burg, M., J. Grantham, M. Abramow, and J. Orloff. 1966. Preparation and study of fragments of single rabbit nephrons. Am. J. Physiol. 210:1293-1298.

27. Rocha, A. S., and J. P. Kokko. 1973. Sodium chloride and water transport in the medullary thick ascending limb of Henle. $J$. Clin. Invest. 52:612-623.

28. MacInnes, D. A. 1961. Galvanic cells with liquid junction potentials. In The Principles of Electrochemistry. D. A. MacInnes, editor. Dover Publications, Inc., New York. 220-245.

29. Jacobson, H. R., and J. P. Kokko. 1976. Intrinsic differences in various segments of the proximal convoluted tubule. J. Clin. Invest. 57:818-825.

30. Friedman, P. A., J. F. Figueiredo, T. Maack, and E. E. Windhager. 1981. Sodium-calcium interactions in the renal proximal convoluted tubule of the rabbit. Am. J. Physiol. 240:F558-F568.

31. Murphy, E., and L. J. Mandel. 1982. Cytosolic free calcium levels in rabbit proximal kidney tubules. Am. J. Physiol. 242:C124C128.

32. Frick, A., and I. Durasin. 1978. Maximal reabsorption capacity for inorganic phosphate ( $\mathrm{TmPi}$ ) in the absence of parathyroid hormone in the rat: decrease of $\mathrm{TmPi}$ during prolonged administration of phosphate and the role of calcium. Pfluegers Arch. 377:9-14.

33. Glorieux, F., and C. R. Scriver. 1972. Loss of a parathyroid hormone-sensitive component of phosphate transport in X-linked hypophosphatemia. Science. (Wash. DC). 175:997-999.

34. Dennis, V. S., E. Bello-Reuss, and R. R. Robinson. 1977. Response of phosphate transport to parathyroid hormone in segments of rabbit nephron. Am. J. Physiol. 233:F29-F38.

35. Brazy, P. C., J. W. McKeown, R. H. Harris, and V. W. Dennis. 1980. Comparative effects of dietary phosphate, unilateral nephrectomy, and parathyroid hormone on phosphate transport by the rabbit proximal tubule. Kidney Int. 17:788-800.

36. McKeown, J. W. 1982. Effects of calcium ionophore A23187 on fluid and phosphate reabsorption in rabbit proximal convoluted tubules (PCT). 15th Annual Meeting Am. Soc. Nephrol., Chicago. 13a. (Abstr.)
37. Popovtzer, M. M., R. S. Flis, S. K. Mehandru, and M. Blum. 1977. Effect of divalent cation ionophore (A23187) on renal handling of phosphorus. Kidney Int. 12:164-171.

38. Cheung, W. Y. 1982. Calmodulin: an overview. Fed. Proc. 41: 2253-2257.

39. Agus, Z. S., J. B. Puschett, D. Senesky, and M. Goldberg. 1971. Mode of action of parathyroid hormone and cyclic adenosine $3^{\prime}, 5^{\prime}$-monophosphate on renal tubular phosphate reabsorption in the dog. J. Clin. Invest. 50:617-626.

40. Kessler, R. J., D. A. Vaughn, and D. D. Fanestil. 1982. Phosphate binding proteolipid from brush border. J. Biol. Chem. 257: 14311-14317.

41. Kessler, R. J., and D. A. Vaughn. 1983. A divalent metal is required for both $\mathrm{Na}^{+}$-driven phosphate uptake in rabbit kidney brush border membrane vesicles (BBMV) and for phosphate binding to a proteolipid isolated from BBMV. Fed. Proc. 42:2242. (Abstr.)

42. McKinney, T. D., and P. Myers. 1982. Effect of calcium and phosphate on bicarbonate and fluid transport by proximal tubules in vitro. Kidney Int. 21:433-438.

43. Crumb, C. K., M. Martinez-Maldonado, G. Eknoyan, and W. N. Suki. 1974. Effects of volume expansion, purified parathyroid extract, and calcium on renal bicarbonate absorption in the dog. $J$. Clin. Invest. 54:1287-1294.

44. Dennis, V. W., P. B. Woodhall, and R. R. Robinson. 1976. Characteristics of phosphate transport in isolated proximal tubule. Am. J. Physiol. 231:979-985.

45. Dennis, V. W., and P. C. Brazy. 1978. Sodium, phosphate, glucose, bicarbonate, and alanine interactions in the isolated proximal convoluted tubule of the rabbit kidney. J. Clin. Invest. 62:387-397.

46. Cheng, L., and B. Sacktor. 1981. Sodium gradient-dependent phosphate transport in renal brush border membrane vesicles. J. Biol. Chem. 256:1556-1564.

47. Hoffman, N., M. Thees, and R. Kinne. 1976. Phosphate transport by isolated renal brush border vesicles. Pfluegers Arch. 362: 147-156.

48. Hamm, I. L., J. P. Kokko, and H. R. Jacobson. 1984. Effect of luminal $\mathrm{pH}$ and $\mathrm{HCO}_{3}^{-}$on phosphate reabsorption in the rabbit proximal convoluted tubule. Am. J. Physiol. 247:F25-F34. 